Section Editor

Robert C. Griggs, MD
Editors' Note: Kalra argues that the post hoc nature of the study, as well as several methodologic flaws, weaken the conclusion that antihypertensive drugs reduce the risk of Alzheimer disease independent of blood pressure reduction. Yasar et al., authors of "Antihypertensive drugs decrease risk of Alzheimer disease: Ginkgo Evaluation of Memory Study," defend their methods and findings.

\section{ANTIHYPERTENSIVE DRUGS DECREASE RISK OF ALZHEIMER DISEASE: GINKGO EVALUATION OF MEMORY STUDY}

Lalit Kalra, London: Yasar et al. ${ }^{1}$ based their article on a secondary analysis of incidental data collected during a published clinical trial on the use of ginkgo biloba to reduce the incidence of dementia. ${ }^{2}$ The authors found that diuretics, angiotensin receptor blockers, and angiotensin-converting enzyme inhibitors, reduced the risk of Alzheimer disease (AD) independent of-or in addition to-mean systolic blood pressure in participants with normal cognition. However, they also found that only diuretic use was associated with reduced risk of $\mathrm{AD}$ in participants with mild cognitive impairment (MCI). These findings are counterintuitive and conflict with existing literature.

Recent randomized controlled studies showed a relationship between blood pressure, white matter disease, and interactions with $\mathrm{AD}$ in dementia progression. ${ }^{2,3}$ It would be difficult to find a biological explanation for the "dementia-reducing" effect of these agents independent of initial blood pressure or blood pressure reduction. Furthermore, the biological plausibility of these agents having a greater effect in people with normal cognition than those with MCI (who are known to progress faster with higher blood pressure levels) is unclear.

A major problem with post hoc analyses is that these data were collected without a firm a priori hypothesis, which introduces a significant element of bias. Further bias is added by the multiple statistical manipulations of several data items, which are likely to produce erroneous results purely by chance in 1 out of every 20 calculations. In addition, there are several methodologic flaws. The main flaw is the lack of assessment of blood pressure at the beginning of the study and no formalized protocol to regularly monitor blood pressure control. Hence, an effect of these agents that is independent of the levels of blood pressure during the period of observation simply cannot be established.

\section{Author Response: Sevil Yasar, Baltimore; Curt Furberg,} Winston-Salem, NC; Claudia Kawas, Irvine, CA; Michelle Carlson, Baltimore: We appreciate the comments by Dr. Kalra and agree that studies with prior hypotheses have higher credibility. However, data from this large-scale trial of a well-defined, nationally representative cohort offer an opportunity to apply methods to study novel risk factors that would be less feasible with smaller samples.

The issue of multiple comparisons was addressed by setting a stricter $p$ value of less than 0.01 . The lack of significant findings among participants with MCI can be explained by the sample size of this group ( $\mathrm{n}=$ 320,110 developed $\mathrm{AD}$ ) compared to the normal group $(\mathrm{n}=1,928,180$ developed $\mathrm{AD})$. In addition, blood pressure was measured at each visit. ${ }^{1}$

Within the limits of secondary data analysis, our results support the possible benefits of antihypertensive medications in addition to the blood pressurelowering effect on the risk of AD. Our study confirms existing data, such as the study by Godin et al., ${ }^{2}$ which examined white matter disease progression in participants with normal cognition. They found no significant difference in baseline white matter lesion (WML) load and WML progression among participants treated with antihypertensive medications independent of blood pressure control.

We believe that antihypertensive medications can exert multiple beneficial effects on $\mathrm{AD}$ risk reduction. (C) 2014 American Academy of Neurology

1. Yasar S, Xia J, Yao W, et al, for the Ginkgo Evaluation of Memory (GEM) Study Investigators. Antihypertensive drugs decrease risk of Alzheimer disease: Ginkgo Evaluation of Memory Study. Neurology 2013;81:896-903.

2. Godin O, Tzourio C, Maillard P, Mazoyer B, Dufouil C. Antihypertensive treatment and change in blood pressure are associated with the progression of white matter lesion volumes: the three-city (3C)-Dijon Magnetic Resonance Imaging Study. Circulation 2011;123:266-273. 
3. Soros P, Whitehead S, Spence JD, Hachinski V. Antihypertensive treatment can prevent stroke and cognitive decline. Nat Rev Neurol 2013;9:174-178.

\section{ANTITHROMBOTIC DRUGS AND RISK OF HEMORRHAGIC STROKE IN THE GENERAL POPULATION}

Simone Vidale, Como, Italy: Garcia-Rodriguez et al. ${ }^{1}$ examined the risk of hemorrhagic stroke in patients treated with antithrombotics. While warfarin increased the risk of both intracerebral hemorrhage $(\mathrm{ICH})$ and subarachnoid hemorrhage $(\mathrm{SAH})$, aspirin did not influence the risk of ICH and surprisingly decreased the frequency of SAH.

The authors did not distinguish between SAH where an aneurysm was identified vs SAH where no aneurysm was found. This would have been useful as previous studies have indicated that aspirin may protect against aneurysm rupture. ${ }^{2}$ In addition, the highest risk of $\mathrm{ICH}$ was found in the short-duration group of warfarin users. This may be due to maintaining a balanced control of anticoagulation at the beginning of the treatment. Similar risk has been observed in recent trials comparing rivaroxaban to warfarin. ${ }^{3}$ It would be interesting to evaluate some characteristics of the patients' international normalized ratio trend-age or concomitant hypertension-to verify other predisposing factors vs the HAS-BLED score.
The addition of an antiplatelet to warfarin does not increase the risk of ICH vs users taking only warfarin. Adding antiplatelets in patients taking warfarin and affected by acute ischemic events might be beneficial by reducing the risk of further thrombotic episodes without the increase in cerebral bleeding risk. In this cohort study, it could be interesting also to identify characteristics (i.e., demographics and vascular risk factors) of patients with ICH treated with antiplatelets and warfarin to detect a risk profile for cerebral hemorrhage.

Finally, in this population-based study, the dual antiplatelet therapy (clopidogrel and aspirin) did not increase the risk of ICH significantly, which conflicts with previous clinical studies. ${ }^{4}$ This finding demonstrates that the "real world" might be better in results than the "trial world."

(C) 2014 American Academy of Neurology

1. Garcia-Rodriguez LA, Gaist D, Morton J, et al. Antithrombotic drugs and risk of hemorrhagic stroke in the general population. Neurology 2013;81:566-574.

2. Hasan DM, Mahaney KB, Brown RD Jr, et al. Aspirin as a promising agent for decreasing incidence of cerebral aneurysm rupture. Stroke 2011;42:3156-3162.

3. Mahaffey KW, Wojdyla D, Hankey G, et al. Clinical outcomes with rivaroxaban in patients transitioned from vitamin $\mathrm{K}$ antagonist therapy: a subgroup analysis of a randomized trial. Ann Intern Med 2013;158:861-868.

4. Field TS, Nakajima M, Benavente OR. Combination aspirin and clopidogrel for secondary prevention of ischemic stroke. Curr Treat Opt Cardiovasc Med 2013;15:348-359.

\section{CORRECTION}

Naive CD4 T-cell activation identifies MS patients having rapid transition to progressive MS

When the original version of the article "Naive CD4 T-cell activation identifies MS patients having rapid transition to progressive MS" by E. Zastepa et al. (Neurology 2014;82:681-690) was published online ahead of print on January 22, 2014, there was an error in table 1 . In the column "SP-1 ( $=6)$," line 2, "Age at MS onset, y (SD)" should have read "30.5 (10.2)." The errors were corrected in version 2, which was posted online ahead of print on February 14, 2014. The authors regret the errors. 


\section{Neurology}

\section{Antihypertensive drugs decrease risk of Alzheimer disease: Ginkgo Evaluation of Memory Study \\ Lalit Kalra, Sevil Yasar, Curt Furberg, et al. Neurology 2014;82;1192-1193 \\ DOI 10.1212/WNL.0000000000000231}

\section{This information is current as of March 31, 2014}

Updated Information \& Services

References

Permissions \& Licensing

Reprints including high resolution figures, can be found at: http://n.neurology.org/content/82/13/1192.full

This article cites 3 articles, 2 of which you can access for free at: http://n.neurology.org/content/82/13/1192.full\#ref-list-1

Information about reproducing this article in parts (figures,tables) or in its entirety can be found online at:

http://www.neurology.org/about/about_the_journal\#permissions

Information about ordering reprints can be found online: http://n.neurology.org/subscribers/advertise

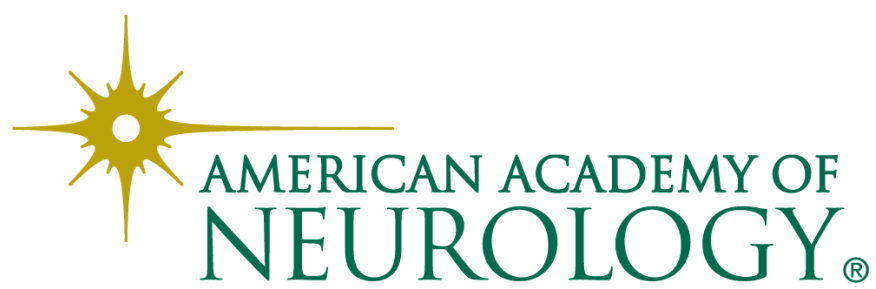

